\title{
AVALIAÇÃO DE GENÓTIPOS DE TOMATEIRO TIPO SANTA CRUZ NO PERÍODO DE VERÃO, EM ARAGUARI, MG'1
}

\author{
JOSÉ RICARDO PEIXOTO ${ }^{2}$, ROGÉRIO PEREIRADA SILVA ${ }^{3}$, FABRÍCIO DE ÁVILARODRIGUES ${ }^{4}$, \\ FERNANDO CÉSAR JULIATTI ${ }^{5}$ e ARTHUR BERNARDES CECÍLIO FILHO ${ }^{6}$
}

\begin{abstract}
RESUMO - O trabalho foi desenvolvido na fazenda Jordão (município de Araguari, MG), na época do verão (período das águas), com o objetivo de verificar o desempenho agronômico de genótipos de tomateiro tipo Santa Cruz. Utilizou-se o delineamento experimental blocos casualizados, com 16 tratamentos (genótipos) e quatro repetições. A parcela experimental foi constituída por duas fileiras com 12 plantas cada, no espaçamento de $1,00 \mathrm{~m}$ entre linhas e $0,55 \mathrm{~m}$ entre plantas ( 1 planta/cova). Efetuaram-se 17 colheitas, sendo a primeira aos 69 dias após o transplante. Vários genótipos apresentaram um bom desempenho agronômico, principalmente Saladinha, Débora Plus, SM-16 e Atlas, podendo ser cultivados no período de verão. Apenas Saladinha e Atlas ultrapassaram $140 \mathrm{~g}$ de peso médio, destacando-se também em frutos do tipo extra AA. Observou-se uma correlação significativa e negativa com $r=-0,52$ e $-0,54$ na primeira avaliação, e $r=-0,55$ e $-0,45$ na segunda avaliação para a produção total e produção comercial, respectivamente, em relação à incidência de geminivírus nos diferentes genótipos. Os híbridos Saladinha e SM-16 apresentaram o menor número de plantas viróticas, enquanto Santa Clara Importada, Santa Clara, Jumbo AG-592 e IAC Santa Clara, apresentaram o maior número.
\end{abstract}

Termos para indexação: tomate, Lycopersicon esculentum, produtividade, qualidade.

\section{EVALUATION OF TOMATO GENOTYPES (SANTA CRUZ TYPE) DURING THE SUMMER SEASON, IN ARAGUARI, MG, BRAZIL}

\begin{abstract}
A field experiment was carried out in the Jordão farm in Araguari, MG, Brazil, during the summer season, to evaluate the agronomic potential of genotypes (Santa Cruz type) of tomato. A randomized block design was used with 16 treatments (genotypes) and four replicates. The experimental plot was made up of two lines $(1.00 \mathrm{~m}$ between lines and $0.55 \mathrm{~m}$ between plants) with 12 plants each (1 plant/pit). Seventeen harvests were made, starting 69 days after transplanting. Several genotypes as Saladinha, Débora Plus, SM-16 and Atlas had a good agronomic performance, being recommended to be cultivated in the region, in the summer season. Classified as AA type, the Saladinha and Atlas showed an average of $140 \mathrm{~g}$ /fruit. During the experiment a negative correlation, $\mathrm{r}=-0.52$ and -0.54 , could be observed, in the first evaluation, and correlation $r=-0.55$ and -0.45 in the second evaluation between total production, and commercial production in relation to geminivirus infection, respectively, for the different genotypes. The Saladinha e SM-16 hybrids showed the lowest number of infected plants, while Santa Clara Imported, Santa Clara, Jumbo AG-592 and IAC Santa Clara showed the highest number.
\end{abstract}

Index terms: tomato, Lycopersicon esculentum, productivity, quality.

\footnotetext{
${ }^{1}$ Aceito para publicação em 29 de março de 1999.

${ }^{2}$ Eng. Agr., Dr., Faculdade de Agronomia e Medicina Veterinária, Universidade de Brasília (UnB), Caixa Postal 04508, CEP 70910-900 Brasília, DF. E-mail: peixoto@unb.br

${ }^{3}$ Eng. Agr., Mestrando em Agronomia, UnB.

${ }^{4}$ Eng. Agr., Mestrando em Agronomia, Universiadade Federal de Viçosa (UFV), CEP 36571-000 Viçosa, MG
}

\footnotetext{
${ }^{5}$ Eng. Agr., Dr., Dep. de Agronomia, Universidade Federal de Uberlândia (UFU), Caixa Postal 593, CEP 38400-902 Uberlândia, MG.

${ }^{6}$ Eng. Agr., Dr., Faculdade de Agronomia, UNESP, Rod. Paulo Donato Castellani, km 5, s/ no , CEP 14870-000 Jaboticabal, SP.
}

Pesq. agropec. bras., Brasília, v.34, n.12, p.2253-2257, dez. 1999 


\section{INTRODUÇÃO}

A cadeia produtiva de tomate passa, atualmente, por importantes mudanças, orientadas para sua modernização. As principais mudanças se referem à introdução de inúmeras variedades, à incorporação de novas tecnologias de produção, à mudança nos canais de comercialização e dos tipos de embalagens, e à expansão das redes de fast food (Melo, 1997). No que diz respeito às variedades, a cultivar Santa Clara ainda é a líder absoluta, com mais de $90 \%$ do mercado. No entanto, a tendência dessa variedade, que domina o mercado brasileiro há mais de meio século, é a de ceder cada vez mais espaço a outros tipos varietais, de introdução recente (Melo, 1997).

O cultivo de verão a céu aberto pode tornar-se economicamente inviável, por ser um período mais favorável à ocorrência de pragas e patógenos, em razão da alta temperatura, pluviosidade e insolação. Temperaturas elevadas também afetam a viabilidade do pólen e podem causar queimaduras e escaldaduras do fruto e a transformação do licopeno em carotenóides, com redução da intensidade da coloração vermelha (Silva Júnior \& Prando, 1989).

Um dos objetivos do melhoramento do tomateiro é a obtenção da resistência múltipla, uma vez que grande parte dos genótipos são sensíveis a vários patógenos de grande relevância econômica. Entre estes, destacam-se os vírus, que são os causadores das principais doenças do tomateiro nas regiões do Triângulo Mineiro e Alto Paranaíba em Minas Gerais, dada a alta proliferação do vetor das geminiviroses que é a mosca-branca (Bemisia spp.). As bactérias também têm causado sérios prejuízos. Segundo Makishima \& Miranda (1992), poucas cultivares de tomate para consumo in natura, disponíveis no mercado brasileiro, apresentam algum grau de resistência a Clavibacter michiganensis subsp. michiganensis (cancro bacteriano). Algumas cultivares tidas como resistentes não têm sido bem aceitas pelos tomaticultores, seja pelo menor tamanho dos frutos, seja pela alta suscetibilidade à podridão apical (Coltri, 1983).

A utilização de híbridos geralmente proporciona aumento na produtividade, além de maturação mais precoce, alto vigor inicial, melhor qualidade dos fru- tos, resistência a doenças e pragas e ampla capacidade de adaptação, em comparação com as cultivares comuns de polinização aberta

Uma linha de pesquisa voltada para a identificação de cultivares (híbridas ou não) que combinem resistência a patógenos e pragas com alta produtividade e tipo de fruto adequado ao consumo in natura (tamanho, formato e aparência externa) é de grande interesse para determinar as melhores cultivares adaptadas às condições edafoclimáticas da região, resultando em maior eficiência dos fatores de produção, e menor uso de insumos, portanto, maior lucro com menor dano ao ambiente.

Este trabalho teve o objetivo de avaliar as características agronômicas de 16 genótipos de tomate do tipo Santa Cruz no verão, em Araguari, MG, que se destaca por ser importante região agrícola do País.

\section{MATERIALE MÉTODOS}

O experimento foi instalado e conduzido na Fazenda Jordão, localizada no município de Araguari, MG, no período de 16/9/95 a 17/2/96 (época das águas).

O município está localizado a $18^{\circ} 38^{\prime} 30^{\prime \prime}$ de latitude sul e $48^{\circ} 11^{\prime} 18^{\prime \prime}$ de longitude oeste de Greenwich. Apresenta uma altitude que varia de $505 \mathrm{~m}$ a $1.087 \mathrm{~m}$ e temperatura média anual de $20,7^{\circ} \mathrm{C}$, sendo a média mínima anual de $16,0^{\circ} \mathrm{C}$, e a média máxima anual de $26,3^{\circ} \mathrm{C}$. A precipitação média anual é de $1.641 \mathrm{~mm}$.

Foram avaliadas as variedades: Ângela Hiper, Concord AG-595, Jumbo AG-592, Kada Gigante, Santa Clara, Santa Clara I-5300, IAC Santa Clara, Santa Clara Importada, Santa Clara III, Tom-556 e os híbridos: Atlas, Cláudia, Débora Plus, Saladinha, SM-16 (dupla finalidade) e Tex-015

A adubação foi realizada segundo as recomendações da Comissão de Fertilidade do Solo do Estado de Minas Gerais (1989) e de acordo com a análise química do solo, que apresentou os seguintes teores: $\mathrm{pH}$ (água) $=6,0$; $\mathrm{P}=4,0 \mathrm{mg} / \mathrm{dm}^{3} ; \mathrm{K}=160 \mathrm{mg} / \mathrm{dm}^{3} ; \mathrm{Al}=0,0 \mathrm{cmol} / \mathrm{dm}^{3}$; $\mathrm{Ca}=4,6 \mathrm{cmol} / \mathrm{dm}^{3} ; \quad \mathrm{Mg}=1,4 \mathrm{cmol} / \mathrm{dm}^{3}$; $\mathrm{H}+\mathrm{Al}=2,6 \mathrm{cmol} / \mathrm{dm}^{3} ; \mathrm{SB}$ (Soma de Bases) $=6,4 \mathrm{cmol} / \mathrm{dm}^{3}$; $\mathrm{t}\left(\mathrm{CTC}\right.$ efetiva/CTC a pH 7,0) $=6,0 \mathrm{cmol} / \mathrm{dm}^{3}$; $\mathrm{T}=9,0 \mathrm{cmol} / \mathrm{dm}^{3} ; \mathrm{V}=71 \% ; \mathrm{m}($ Sat. de $\mathrm{Al})=0 \%$ e matéria orgânica-M.O. (Walkley-Black) $=2,9 \mathrm{dag} / \mathrm{kg}$.

No plantio, foram utilizados, em cada metro linear de sulco, aproximadamente $2 \mathrm{~kg}$ de esterco de curral curtido, $300 \mathrm{~g}$ de superfosfato simples, $30 \mathrm{~g}$ de cloreto de potássio e $10 \mathrm{~g}$ de FTE. 
Realizaram-se quatro adubações de cobertura via solo, iniciando-se na terceira semana após o transplante e repetindo a cada 14 dias de intervalo, utilizando-se, em cada aplicação, $25 \mathrm{~g} /$ planta de sulfato de amônio, $25 \mathrm{~g} /$ planta de nitrocálcio, e $15 \mathrm{~g} /$ planta de cloreto de potássio, e foliar (Orgamin a $0,02 \%$ e Ouro Verde a $0,01 \%$ ). As sementes foram obtidas junto a empresas especializadas. As mudas foram formadas em bandejas de isopor tipo "sped elling" com 128 células, contendo substrato composto por vermiculita e casca de Pinus sp. O transplante foi feito para um campo, recém-preparado, utilizando-se o espaçamento $1,00 \times 0,55 \mathrm{~m}$, com 1 planta/cova, conduzidas no sistema de duas hastes por planta.

Foram efetuados todos os tratos fitossanitários e culturais indispensáveis a esta cultura, tais como tutoramento do tipo cerca cruzada, desbrotas semanais, amarrios, amontoa e desponte. A irrigação foi feita por infiltração em turno de rega de três dias

Utilizou-se o delineamento experimental de blocos casualizados, com 16 tratamentos (16 genótipos) e quatro repetições, sendo a parcela constituída de 24 plantas. Foram feitas 17 colheitas, a partir do 69음 dia após o transplante, sendo duas por semana, prolongando-se por oito semanas. Avaliou-se o número de frutos por planta; porcentagem do número de frutos classificados em extra AA e extra A; peso médio dos frutos; produtividade total e comercial, e incidência de viroses, obtendo-se a porcentagem de plantas com sintomas visíveis (aos 49 e 64 dias após o transplante). A classificação foi de acordo com as exigências do mercado local quanto à aparência e ao tamanho do fruto.

As análises empregadas para avaliação dos resultados foram baseadas em modelo apropriado para o delineamento utilizado, de acordo com Pimentel-Gomes (1978). Todos os dados originais foram submetidos a análise de variância, utilizando-se para o teste de F, os níveis de 5 e $1 \%$ de probabilidade. As médias foram comparadas entre si, pelo teste de Tukey, a $5 \%$ de probabilidade.

\section{RESULTADOS E DISCUSSÃO}

Os híbridos Saladinha e Débora Plus, de forma geral, se destacaram em relação aos demais genótipos, enquanto, Kada Gigante, Jumbo AG-592 e Ângela Hiper, tiveram um comportamento inferior, praticamente em todos os aspectos. Houve uma diferença na produtividade de $258,75 \%$ entre o genótipo mais produtivo (Saladinha) e o menos produtivo (Kada Gigante) (Tabelas 1 e 2).
Em termos gerais, os seis híbridos superaram os demais genótipos em produtividade total, variando de $63,1 \mathrm{t} / \mathrm{ha}$ a $91,7 \mathrm{t} / \mathrm{ha}$, sendo que apenas quatro deles (Saladinha, Débora Plus, SM-16 e Atlas) produziram mais de $55 \mathrm{t} / \mathrm{ha}$ de frutos comerciais e tiveram as menores porcentagens de perda (abaixo de 16,33\%) (Tabela 1). Silva Júnior et al. (1995) verificaram maior produção comercial das cultivares Débora, Jumbo, Santa Clara e Cláudia, com rendimentos acima de $72 \mathrm{t} / \mathrm{ha}$ em trabalho realizado no município de Itajaí, SC.

Nove genótipos tiveram o peso médio de frutos igual ou superior a $120 \mathrm{~g}$; apenas dois híbridos (Saladinha e Atlas) ultrapassaram $140 \mathrm{~g}$ (Tabela 1). Embora tenha sido a cultivar mais produtiva, para as condições edafoclimáticas do litoral de Itajaí, SC, a cultivar Débora apresentou menor peso médio de frutos em relação aos materiais mais promissores, Silva Júnior et al. (1995).

Para número de frutos comerciais, os híbridos Saladinha e Débora Plus, também se destacaram com média superior a 30 frutos/planta e, na classificação para o comércio, Saladinha, SM-16 e Atlas tiveram mais de $60 \%$ de frutos tipo extra $\mathrm{AA}$, enquanto Tex-015, Tom-556, Ângela Hiper e Kada Gigante tiveram mais de $72 \%$ de frutos tipo extra A, demonstrando a grande quantidade de frutos de menor qualidade nestes genótipos (Tabela 2). Silva Júnior et al. (1995) verificaram maior uniformidade de produção de frutos graúdos nas cultivares Débora e Jumbo.

O híbrido Tex-015, apesar de produtivo apresentou uma alta porcentagem de frutos não comerciais e baixa porcentagem de frutos tipo extra AA (Tabelas 1 e 2).

As cultivares Santa Clara comercializadas por diversas empresas com várias denominações (Santa Clara, Santa Clara Importada, IAC Santa Clara, Santa Clara III e Santa Clara I-5300) tiveram um comportamento intermediário, e não diferiram entre si. Sob melhores condições edafoclimáticas, é esperado que tais cultivares apresentem melhor desempenho em produtividade e qualidade de frutos.

Observou-se correlação significativa e negativa com $r=-0,52$ e $-0,54$ na primeira avaliação $e$ $\mathrm{r}=-0,55$ e $-0,45$ na segunda avaliação, para a produção total e produção comercial de tomate, res- 
TABELA 1. Produtividade total e comercial, porcentagem de perda, e peso médio de frutos de tomate de 16 genótipos tipo Santa Cruz, colhidos no período de verão, em Araguari, MG, 1995'.

\begin{tabular}{llcll}
\hline Genótipo & \multicolumn{3}{c}{ Produtividade (t/ha) } & Peso médio \\
\cline { 2 - 4 } & Total & Comercial & Perda $(\%)$ & $141,0 \mathrm{a}$ \\
\hline Saladinha & $91,7 \mathrm{a}$ & $79,2 \mathrm{a}$ & $13,51 \mathrm{f}$ & $117,3 \mathrm{bc}$ \\
Débora Plus & $78,5 \mathrm{ab}$ & $66,9 \mathrm{ab}$ & $14,94 \mathrm{f}$ & $126,3 \mathrm{~b}$ \\
SM-16 & $69,5 \mathrm{bc}$ & $58,1 \mathrm{bc}$ & $16,33 \mathrm{ef}$ & $102,7 \mathrm{~d}$ \\
Tex-015 & $68,2 \mathrm{bcd}$ & $48,0 \mathrm{~cd}$ & $29,93 \mathrm{bc}$ & $143,8 \mathrm{a}$ \\
Atlas & $65,2 \mathrm{bcde}$ & $55,2 \mathrm{bcd}$ & $15,38 \mathrm{ef}$ & $110,5 \mathrm{~cd}$ \\
Cláudia & $63,1 \mathrm{bcdef}$ & $48,9 \mathrm{~cd}$ & $22,34 \mathrm{cdef}$ & $122,8 \mathrm{bc}$ \\
Concord & $63,0 \mathrm{bcdef}$ & $49,9 \mathrm{~cd}$ & $21,02 \mathrm{cdef}$ & $121,5 \mathrm{bc}$ \\
Santa Clara I-5300 & $62,9 \mathrm{bcdef}$ & $51,3 \mathrm{bcd}$ & $18,77 \mathrm{def}$ & $121,2 \mathrm{bc}$ \\
Santa Clara III & $60,0 \mathrm{cdef}$ & $48,9 \mathrm{~cd}$ & $18,83 \mathrm{def}$ & $100,1 \mathrm{~d}$ \\
Tom-556 & $57,9 \mathrm{cdef}$ & $42,0 \mathrm{de}$ & $27,54 \mathrm{bcd}$ & $122,1 \mathrm{bc}$ \\
IAC Santa Clara & $54,6 \mathrm{cdef}$ & $43,0 \mathrm{cde}$ & $21,36 \mathrm{cdef}$ & $120,0 \mathrm{bc}$ \\
Santa Clara & $52,5 \mathrm{defg}$ & $42,2 \mathrm{cde}$ & $19,85 \mathrm{cdef}$ & $119,1 \mathrm{bc}$ \\
Santa Clara Importada & $49,6 \mathrm{defg}$ & $39,5 \mathrm{de}$ & $20,53 \mathrm{cdef}$ & $101,7 \mathrm{~d}$ \\
Angela Hiper & $48,8 \mathrm{fg}$ & $31,3 \mathrm{ef}$ & $35,67 \mathrm{ab}$ & $120,0 \mathrm{bc}$ \\
Jumbo AG-592 & $37,4 \mathrm{~g}$ & $27,9 \mathrm{ef}$ & $25,26 \mathrm{cde}$ & $99,2 \mathrm{~d}$ \\
Kada Gigante & $37,4 \mathrm{~g}$ & $22,1 \mathrm{f}$ & $41,02 \mathrm{a}$ & 11,5 \\
\hline C.V. (\%) & 10,7 & 13,2 & 17,6 & \\
\hline
\end{tabular}

${ }^{1}$ Médias seguidas pela mesma letra, nas colunas, não diferem estatisticamente, entre si, pelo teste de Tukey, a $5 \%$ de probabilidade.

TABELA 2. Frutos comerciais/planta e frutos do tipo extra AA e extra A, de tomate de 16 genótipos tipo Santa Cruz, colhidos no período de verão, em Araguari, MG, $1995^{1}$.

\begin{tabular}{lccc}
\hline Genótipo & $\begin{array}{c}\text { Frutos comerciais/planta } \\
\left(\mathrm{n}^{\circ}\right)\end{array}$ & $\begin{array}{c}\text { Frutos tipo extra AA } \\
(\%)\end{array}$ & $\begin{array}{c}\text { Frutos tipo extra A } \\
(\%)\end{array}$ \\
\hline Saladinha & $30,1 \mathrm{ab}$ & $64,2 \mathrm{a}$ & $35,8 \mathrm{~g}$ \\
Débora Plus & $32,1 \mathrm{a}$ & $40,8 \mathrm{~cd}$ & $59,2 \mathrm{de}$ \\
SM-16 & $23,2 \mathrm{bcd}$ & $60,5 \mathrm{ab}$ & $39,5 \mathrm{fg}$ \\
Tex-015 & $25,4 \mathrm{abc}$ & $24,1 \mathrm{fg}$ & $75,9 \mathrm{ab}$ \\
Atlas & $21,3 \mathrm{cde}$ & $63,3 \mathrm{a}$ & $36,7 \mathrm{~g}$ \\
Cláudia & $22,9 \mathrm{bcd}$ & $39,2 \mathrm{de}$ & $60,8 \mathrm{~cd}$ \\
Concord & $22,2 \mathrm{~cd}$ & $52,3 \mathrm{abc}$ & $47,7 \mathrm{efg}$ \\
Santa Clara I-5300 & $22,6 \mathrm{bcd}$ & $48,9 \mathrm{bcd}$ & $51,1 \mathrm{def}$ \\
Santa Clara III & $22,4 \mathrm{bcd}$ & $50,1 \mathrm{bcd}$ & $49,9 \mathrm{def}$ \\
Tom-556 & $22,1 \mathrm{~cd}$ & $27,0 \mathrm{ef}$ & $73,0 \mathrm{bc}$ \\
IAC Santa Clara & $19,7 \mathrm{cdef}$ & $46,0 \mathrm{~cd}$ & $54,0 \mathrm{de}$ \\
Santa Clara & $19,8 \mathrm{cdef}$ & $45,6 \mathrm{~cd}$ & $54,4 \mathrm{de}$ \\
Santa Clara Importada & $48,5 \mathrm{bcd}$ & $51,5 \mathrm{def}$ \\
Ângela Hiper & $17,6 \mathrm{cdef}$ & $18,7 \mathrm{fg}$ & $81,3 \mathrm{ab}$ \\
Jumbo AG-592 & $16,8 \mathrm{def}$ & $41,0 \mathrm{~cd}$ & $59,0 \mathrm{de}$ \\
Kada Gigante & $13,6 \mathrm{ef}$ & $13,0 \mathrm{~g}$ & $87,0 \mathrm{a}$ \\
\hline C.V. (\%) & $13,0 \mathrm{f}$ & 8,6 & 4,3 \\
\hline
\end{tabular}

${ }^{1}$ Médias seguidas pela mesma letra, nas colunas, não diferem estatisticamente, entre si, pelo teste de Tukey, a $5 \%$ de probabilidade. 
pectivamente, em relação a incidência de viroses nas diferentes cultivares. Os híbridos Saladinha e SM-16 apresentaram o menor número de plantas viróticas com 2,5 e 3,0\%, respectivamente, enquanto que Santa Clara Importada, Santa Clara, Jumbo AG-592 e IAC Santa Clara, apresentaram o maior número de plantas viróticas com 50,0, 47,0, 44,0 e $40,0 \%$, respectivamente. Portanto, a virose foi um dos fatores que influenciou a produtividade destes genótipos.

Observaram-se danos causados pelo inseto Tuta absoluta (traça-do-tomateiro) e pelo ataque do fungo Alternaria solani (causando pinta preta na parte basal do caule e nas folhas inferiores) em todas as cultivares, e em todas as plantas. Apesar de estes problemas fitossanitários terem sido intensos e favorecidos pela época chuvosa, foram contornados com aplicação de fungicidas/bactericidas e inseticidas/acaricidas. Porém, a produtividade e a qualidade dos materiais testados foi bastante prejudicada, principalmente dos materiais mais sensíveis, como é o caso do Santa Clara.

Em linhas gerais, os híbridos se destacaram em relação aos demais materiais, presumivelmente em virtude das vantagens que estes apresentam, especialmente em termos da aparente resistência a patógenos e pragas.

\section{CONCLUSÕES}

1. Os genótipos Saladinha, Débora Plus e Atlas, além do tradicional Santa Clara, apresentaram características agronômicas superiores e são recomendados para a região de Araguari no período de verão.

2. Os híbridos Saladinha e Débora Plus apresentam melhor desempenho agronômico do que a cultivar Santa Clara.

\section{AGRADECIMENTOS}

Às empresas que forneceram as sementes (HortiAgro, Agroceres, Agroflora, Topseed, Isla, Asgrow); aos senhores Rui Alves Peixoto (produtor rural), Rui Alves Peixoto Júnior, Joaquim Lopes (Auxiliar Técnico da UFU), Rinaldo Alves Peixoto, Vanderlei Batista da Silva e Júnio Batista Carneiro, pela valiosa ajuda na instalação, condução e avaliações do experimento.

\section{REFERÊNCIAS}

COLTRI, M.L. Efeito do cancro bacteriano (Corynebacterium michiganense pv. michiganense (Smith) Jensen) em cultivares de tomateiro (Lycopersicon esculentum Mill). Botucatu: UNESP, 1983. 62p. Dissertação de Mestrado

COMISSÃO DE FERTILIDADE DO SOLO DO ESTADO DE MINAS GERAIS. Recomendações para o uso de corretivos e fertilizantes em Minas Gerais, 4a aproximação. Lavras, 1989. 176p.

MAKISHIMA, N.; MIRANDA, J.E.C. Cultivo do tomate (Lycopersicon esculentum Mill). Brasília: EmbrapaCNPH, 1992. 22p. (Instruções Técnicas, 11).

MELO, P.C.T. de. Do canteiro à mesa, muitas novidades. Agrianual 97 - Anuário da Agricultura Brasileira, São Paulo, p.402-404, 1997.

PIMENTEL-GOMES, F. Curso de Estatística Experimental. 8.ed. São Paulo: Nobel, 1978. 430p.

SILVA JÚNIOR, A.A.; PRANDO, H.F. Cultivares e épocas de semeadura de tomate para o litoral catarinense. Agropecuária Catarinense, Santa Catarina, v.9, n. 4 , p.48-50, set. 1989 .

SILVA JÚNIOR, A.A.; VIZZOTO, V.J.; STUKER, H. Cultivares de tomate para o Baixo Vale do Itajaí. Agropecuária Catarinense, Santa Catarina, v.8, n.4, p.35-39, dez. 1995. 